\title{
Surgical experience of hepatectomy in a live donor with absent celiac trunk - a case report
}

\author{
Fizzah Arif ${ }^{*}$ (D), Shah Muhammad, Muhammad Arsalan Khan and Abdaal Waseem Khan
}

\begin{abstract}
Background: Celiac trunk agenesis is the recent and the rarest vascular variation reported. Reported cases in literature were identified either incidentally on imaging or while cadaveric dissections. This is a unique experience of hepatectomy in a patient without celiac artery ever reported.

Case presentation: This is a case of a patient who was scheduled to undergo donor hepatectomy. He was found to have a rare anatomical variation of agenesis of the celiac trunk during preoperative imaging done as a routine transplant surgery workup. He underwent live donor hepatectomy with no intra-operative or post-operative complications. This is the first case to be reported in the literature of a donor hepatectomy for liver transplantation in a patient with this rarest vascular variation of the celiac axis.
\end{abstract}

Conclusion: Pre-operative imaging to determine hepatic vascular anatomy improves the understanding of the surgeon intraoperatively while dissection and decreases the chance of any iatrogenic damage.

Keywords: Liver transplant, Agenesis of the celiac trunk, Anatomical variation, Hepatic artery, Celiac artery, Case report

\section{Background}

Different anatomical variations of the celiac artery have been recognized and reported in the literature with agenesis of the celiac trunk being the rarest anomaly $(0.1-2.6 \%)[1,2]$. The first case of the absent celiac trunk was reported in the year 1832 [3].

Earlier classifications of the celiac artery did not include the missing celiac artery as a variant $[4,5]$. As per Morita's classification [1, 4], this case belongs to type V (typus primitus). Adequate pre-operative workup helped surgeons in understanding the vascular anatomy intraoperatively and therefore, after mutual consensus of transplant team it was decided that no alteration in the standard surgical plan was needed in this donor. A standard hilar dissection for the left hepatic lobectomy was performed. No attempt was thus made to dissect

\footnotetext{
* Correspondence: aarif.fizzah@gmail.com

Department of General Surgery, Sindh Institute of Urology and Transplantation, Karachi, Pakistan
}

\section{Springer Open}

(C) The Author(s). 2021 Open Access This article is licensed under a Creative Commons Attribution 4.0 International License, which permits use, sharing, adaptation, distribution and reproduction in any medium or format, as long as you give appropriate credit to the original author(s) and the source, provide a link to the Creative Commons licence, and indicate if changes were made. The images or other third party material in this article are included in the article's Creative Commons licence, unless indicated otherwise in a credit line to the material. If material is not included in the article's Creative Commons licence and your intended use is not permitted by statutory regulation or exceeds the permitted use, you will need to obtain permission directly from the copyright holder. To view a copy of this licence, visit http://creativecommons.org/licenses/by/4.0/. the aortic origin of the three separate vessels replacing the celiac trunk.

\section{Case presentation}

A 38-year-old male with no known comorbid, was planned for liver donation, underwent routine preoperative evaluation before hepatectomy for a liver transplant. CT angiography and volumetry was done to visualize the vascular anatomy of the hepatobiliary system. On reviewing the images, celiac trunk was absent and was replaced by left gastric, common hepatic, and splenic arteries originating separately from the aorta (Fig. 1). The left gastric artery was the first branch to arise, followed by the common hepatic artery $(5.8 \mathrm{~mm}$ in diameter and $16.5 \mathrm{~mm}$ in length) (Fig. 2). Common hepatic artery bifurcated into gastroduodenal artery and hepatic artery proper $(4.5 \mathrm{~mm}$ in diameter). Hepatic artery proper divided into right hepatic artery $(3.7 \mathrm{~mm}$ in diameter and $43.9 \mathrm{~mm}$ in length) and left hepatic artery 


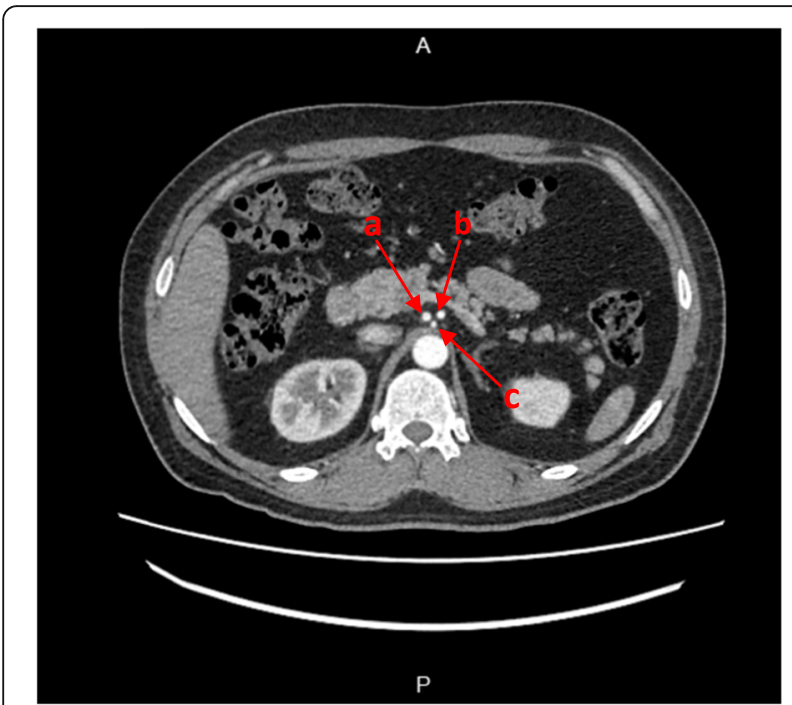

Fig. 1 Abdominal CT scan (contrast) in arterial phase demonstrating the common hepatic artery (a), splenic artery (b), and left gastric artery (c) arising independently from the abdominal aorta
(1.7 $\mathrm{mm}$ in diameter and $41.8 \mathrm{~mm}$ in length) (Fig. 3). A branch from right hepatic artery was supplying segment IV ( $2 \mathrm{~mm}$ in diameter and $42.0 \mathrm{~mm}$ in length). Venous anatomy was unremarkable except two accessory hepatic veins noted in segment VI (7.3 $\mathrm{mm}$ in diameter) and segment VII (2.6 $\mathrm{mm}$ in diameter). Total liver volume was $1832.95 \mathrm{cc}$ (right lobe $=1386.22 \mathrm{cc}$, left lobe $=419 \mathrm{cc}$, caudate lobe $=27.73 \mathrm{cc}$ ). The splenic artery originated at the same level as the common hepatic artery, but it was directed to the left toward the spleen. All other relevant pretransplant workup was normal.

The patient had unremarkable donor hepatectomy with no adverse intra-operative event. He remained stable post procedure and was discharged within few days.

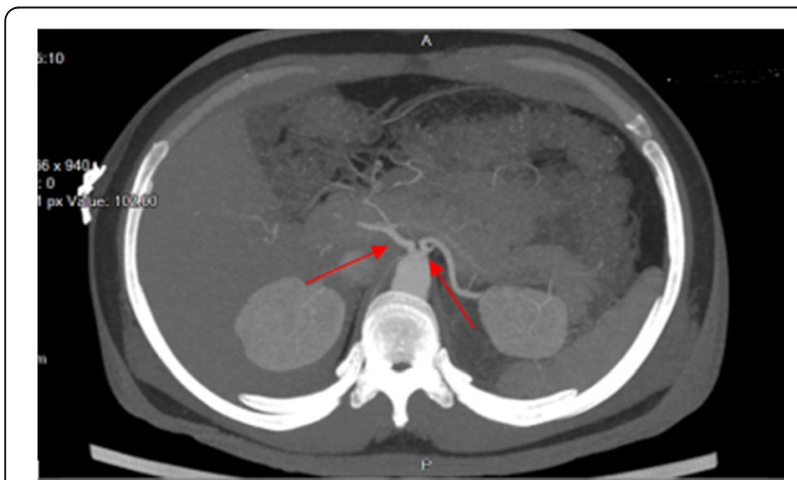

Fig. 2 Abdominal CT scan axial image showing the separate origin of the common hepatic artery and splenic artery from the aorta

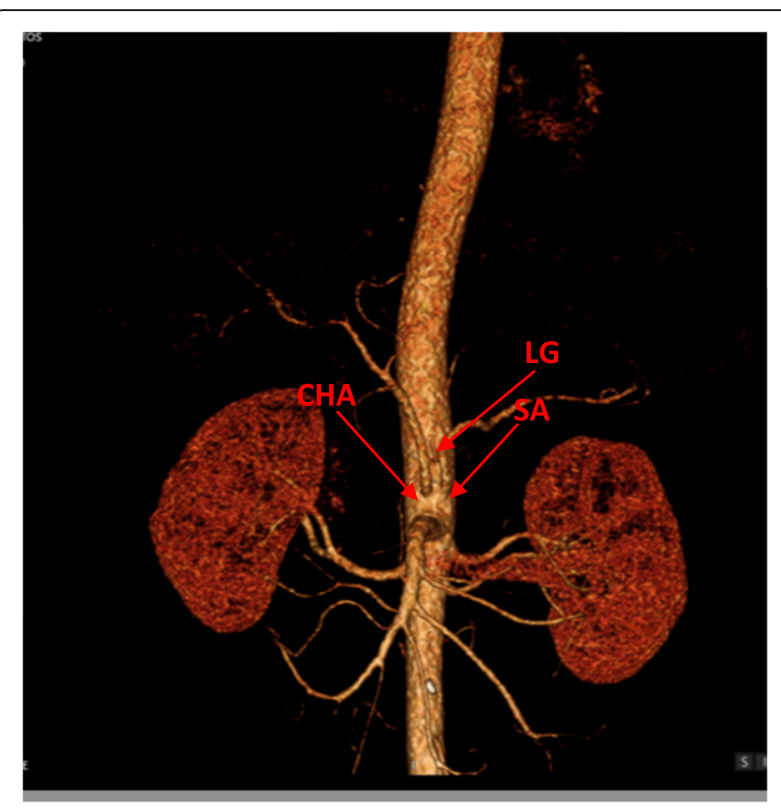

Fig. 3 Coronal CT Angiogram displaying origination of common hepatic artery $(\mathrm{CHA})$, left gastric artery $(\mathrm{LGA})$, and splenic artery $(\mathrm{SA})$, separately from abdominal aorta

\section{Discussion}

Pattern of Tripus Halleri (trifurcation) of the coeliac trunk was first described by Haller in 1756. Normally, the celiac artery branches into the left gastric artery, the common hepatic artery, and the splenic artery [1]. Classical trifurcation of the celiac artery has been reported in $87.6 \%$ of the cadavers, and $12.4 \%$ had variable patterns [3]. Agenesis of the celiac trunk is a rare vascular anomaly with a mean prevalence of $0.38 \%$ [6]. The first case of the absent celiac artery was reported in 1832 by Geoffory Saint-Hilaire [3]. Aortic origination of all branches of the celiac axis is seen in $2 \%$ of cases [7]. In a systematic review of anatomical variation of celiac artery, 5 cases $(41.7 \%)$ of the absent celiac trunk were identified out of total of 12 studies [2]. Nearly, 33\% of these cases are diagnosed on radiological imaging [1]. $0.19 \%$ of 10750 CT scans had absent celiac trunk [4].

Various theories have been explained regarding the missing celiac trunk. It is believed that formative changes of ventral splanchnic arteries that have originated from paired ventral segmental arteries are responsible for morphological types of the celiac axis. The celiac trunk develops from the union of longitudinal anastomoses of segmental arteries. The absence of these anastomoses leads to the remnant of the segmental arteries and subsequent agenesis of the celiac trunk [4].

Initially, anatomical variants of the celiac trunk were classified by Lipshutz (1917) and Adachi (1928). Lipshutz described four variations of the celiac trunk: type I: coeliac artery branches into gastric, splenic, and 
hepatic arteries; type II: hepatic and splenic arteries arise from the coeliac axis and the gastric artery originates from the abdominal aorta; type III: the gastric and hepatic arteries arise from the coeliac axis whereas, the splenic artery separately branch from the abdominal aorta; and type IV: the gastric and the splenic arteries branch from the celiac artery and the hepatic artery comes from the abdominal aorta [5]. Adachi classified six types: (i) hepatogastrosplenic, (ii) hepatosplenic, (iii) gastrosplenic, (iv) coeliacomesenteric, (v) hepatosplenomesenteric, and (vi) hepatomesenteric [5].

Agenesis of the celiac trunk was not described in either of these classification systems of the celiac trunk. Morita proposed a modified version of the celiac axis classification which included absent celiac artery as one of the anatomical variants. Morita's classification included (i) celiac trunk, (ii) hepatosplenic, (iii) gastrosplenic, (iv) hepatogastric, and (v) absent celiac trunk $[1,4]$.

According to Morita's classification (1935), the presented case belongs to type V (Typus primitivus). Preoperative knowledge of abdominal vascular anatomy in this case helped in careful identification and dissection of the left hepatic hilar structures during left donor hepatectomy. That included the left hepatic artery, the separate segment IV hepatic artery, the left hepatic duct, and the left portal vein. Following a careful dissection of these structures and the parenchymal dissection, ligation of the left hepatic artery and segment IV hepatic artery (arising from the right hepatic artery) were key steps in this case of donor hepatectomy. Failure to identify the common hepatic artery can lead to devastating effects on the vascularity of the remaining liver parenchyma in a live donor. The rest of the surgery was carried out without any special intervention or maneuver, with regards to vascular morphology.

This case highlights the importance of pre-transplant imaging as vascular variations when encountered intraoperatively can be challenging for the surgeon; also, CT imaging aids in preventing inaccurate resection and hence reducing donor-related morbidity and mortality.

\section{Conclusion}

This case report depicts the importance of pre-operative radiological techniques in patients planned for liver transplant as various anatomical varieties of celiac axis exist and precise details of hepatic vasculature help in the planning of surgery in live hepatic donors for transplant.

\section{Abbreviations}

MD-CT: Multi-detector CT scan
Authors' contributions

FA: Manuscript writing/editing. SM: Manuscript writing/editing/reviewing. MAK: Manuscript writing/editing/reviewing. AWK: Manuscript writing/editing/ reviewing. The authors have read and approved the final manuscript.

\section{Funding}

None.

Availability of data and materials

Not applicable

\section{Declarations}

Ethics approval and consent to participate

Approved by SIUT-Ethical Review Committee (SIUT-ERC).

\section{Consent for publication}

Taken from the patient.

\section{Competing interests}

The authors declare that they have no competing interests.

Received: 26 November 2020 Accepted: 3 May 2021

Published online: 12 May 2021

References

1. Fahmy D, Sadek H (2015) A case of absent celiac trunk: case report and review of the literature. Egypt J Radiol Nucl Med 46(4):1021 Available from: https://www.sciencedirect.com/science/article/pii/S0378603X15001424

2. Santos P, Barbosa A, Targino VA, Silva NA, Silva Y, Barbosa F, Oliveira A, Assis TO (2018) Anatomical variations of the celiac trunk: a systematic review. Arquivos brasileiros de cirurgia Digest 31(4):e1403. https://doi.org/10.1590/ 0102-672020180001e1403

3. Yi S-Q, Terayama H, Naito M, Hirai S, Alimujang S, Yi N et al (2008) Absence of the celiac trunk: case report and review of the literature. Clin Anat 21(4): 283 (New York, N.Y.). U.S. National Library of Medicine. Available from: https://www.ncbi.nlm.nih.gov/pubmed/18428985

4. Van den broecke M, Leenknegt B, Delrue L (2019) Absence of the Celiac Trunk. J Belgian Soc Radiol 103(1):15. https://doi.org/10.5334/jbsr.1732

5. Matusz P, Miclaus GD, Ples H, Tubbs RS, Loukas M (2012) Absence of the celiac trunk: case report using MDCT angiography. Surg Radiol Anat 34:959 Available from: https://www.ncbi.n/m.nih.gov/pubmed/22689084

6. Pinal-Garcia DF, Nuno-Guzman CM, Gonzalez-Gonzalez ME, Ibarra-Hurtado TR (2018) The celiac trunk and its anatomical variations: a cadaveric study. J Clin Med Res 10(4):321-329. https://doi.org/10.14740/jocmr3356w

7. Rastogi R, Gupta Y, Wani AM, Joon P, Parashar S et al (2016) Elephant trunk sign of Rajul: a rare radiological finding in agenesis of celiac axis. J Gastro Hepato Dis 2(1):110. https://doi.org/10.19104/jghd.2016.110

\section{Publisher's Note}

Springer Nature remains neutral with regard to jurisdictional claims in published maps and institutional affiliations.

\section{Submit your manuscript to a SpringerOpen ${ }^{\circ}$ journal and benefit from:}

- Convenient online submission

- Rigorous peer review

- Open access: articles freely available online

- High visibility within the field

- Retaining the copyright to your article

Submit your next manuscript at $\boldsymbol{\nabla}$ springeropen.com 